\title{
Article
}

\section{Design of conformal cooling layers with self-supporting lattices for additively manufactured tooling}

Brooks, Hadley Laurence

Available at http://clok.uclan.ac.uk/17993/

Brooks, Hadley Laurence ORCID: 0000-0001-9289-5291 (2016) Design of conformal cooling layers with self-supporting lattices for additively manufactured tooling. Additive Manufacturing, 11 . pp. 16-22. ISSN 2214-7810

It is advisable to refer to the publisher's version if you intend to cite from the work. http://dx.doi.org/10.1016/j.addma.2016.03.004

For more information about UCLan's research in this area go to http://www.uclan.ac.uk/researchgroups/ and search for < name of research Group>.

For information about Research generally at UCLan please go to http://www.uclan.ac.uk/research/

All outputs in CLoK are protected by Intellectual Property Rights law, including Copyright law. Copyright, IPR and Moral Rights for the works on this site are retained by the individual authors and/or other copyright owners. Terms and conditions for use of this material are defined in the policies page.

\section{CLoK}

Central Lancashire online Knowledge www.clok.uclan.ac.uk

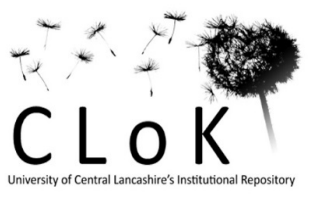




\section{Accepted Manuscript}

Title: Design of conformal cooling layers with self-supporting lattices for additively manufactured tooling

Author: Hadley Brooks Kevin Brigden

PII: $\quad$ S2214-8604(16)30040-9

DOI: $\quad$ http://dx.doi.org/doi:10.1016/j.addma.2016.03.004

Reference: $\quad$ ADDMA 72

To appear in:

Received date: 9-9-2015

Revised date: $\quad 22-1-2016$

Accepted date: $\quad$ 21-3-2016

Please cite this article as: $\{\mathrm{http} / / / \mathrm{dx} . \mathrm{doi} . o r g /$

This is a PDF file of an unedited manuscript that has been accepted for publication. As a service to our customers we are providing this early version of the manuscript. The manuscript will undergo copyediting, typesetting, and review of the resulting proof before it is published in its final form. Please note that during the production process errors may be discovered which could affect the content, and all legal disclaimers that apply to the journal pertain. 
Title: Design of Conformal Cooling Layers with Self-supporting Lattices for Additively Manufactured Tooling

${ }^{*}$ Hadley Brooks ${ }^{a}$, Kevin Brigden ${ }^{b}$

${ }^{a, b}$ School of Engineering, University of Central Lancashire, United Kingdom

*Corresponding author: hlbrooks@uclan.ac.uk

Abstract:

Additively manufactured (AM) conformal cooling channels are currently the state of the art for high performing tooling with reduced cycle times. This paper introduces the concept of conformal cooling layers which challenges the status quo in providing higher heat transfer rates that also provide less variation in tooling temperatures.

The cooling layers are filled with self-supporting repeatable unit cells that form a lattice throughout the cooling layers. The lattices increase fluid vorticity which improves convective heat transfer. Mechanical testing of the lattices shows that the design of the unit cell significantly varies the compression characteristics.

A virtual case study of the injection moulding of a plastic enclosure is used to compare the performance of conformal cooling layers with that of conventional (drilled) cooling channels and conformal (AM) cooling channels. The results show the conformal layers reduce cooling time by $26.34 \%$ over conventional cooling channels.

Keywords: Conformal cooling, Additive manufacturing, Injection moulding, Finite Element Analysis; Tooling

1. Introduction

Many manufacturing processes require the careful control of surface temperatures, and heat transfer rates, to increase production and improve product quality. Injection moulding, blow moulding, die 
casting and extrusion are all examples of manufacturing processes that can benefit from incorporating methods of increased and balanced heat transfer within the tooling.

For injection moulding, heat transfer is usually carried out using straight cooling channels drilled into the mould. Due to conventional manufacturing constraints it is often difficult, or impossible, to position these channels close to the surface of the cavity in a way that provides optimal heat transfer. Increasingly, additive manufacturing (AM) is being used to produce conformal cooling channels in moulds and mould inserts. Powder bed techniques that utilise binders, lasers or electron beams, known variously as 3D printing, Direct Metal Laser Sintering (DMLS), Selective Laser Melting (SLM), Laser Cusing, and Electron Beam Melting (EBM), have a proven ability to produce highly complex cooling channels capable of reducing cooling times. As cooling accounts for a large portion of the total cycle time, this can lead to significant cost savings. Schmidt et al. [1] showed in one case study that 3D printed conformal cooling tool inserts reduced cooling and cycle times by $19-20 \%$ over conventionally machined inserts.

Many other manufacturing processes may also benefit from advanced thermal management of the tooling. Shayfull et al. [2] concluded that rapid heat cycle moulding, in which the mould is heated and cooled for each cycle is also likely to benefit greatly from conformal cooling, however this is yet to be fully explored. Au and Yu carried out computer aided engineering simulations to demonstrate the benefits of conformal cooling over conventional cooling for blow moulding tooling [3]. Hölker et al. showed that conformal cooling of extrusion dies could reduce surface defects on the extruded material [4]. Armillotta et al. showed that conformal cooling improves the surface quality of die cast parts, reduces cycle time and reduces part porosity [5].

As additively manufactured tooling is becoming more mainstream, research has shifted from case studies which show the benefits of conformal cooling, to design automation and optimisation. The more design freedoms the manufacturing process allows, the larger the solution space and the more challenging it is to design an optimal solution. Typically, conformal cooling channels are designed iteratively, using simulation software to evaluate mould performance and provide information for the next iteration. While this method often leads to high performance it requires substantial design time and can result in extremely complicated cooling circuits. Wang et al. developed a method of automatically generating conformal cooling circuits based on Centroidal Voronoi Diagram meshes [6]. 
The tooling was not experimentally tested, however, simulations showed reduced cooling time and improved uniformity of temperature and volumetric shrinkage. Au et al developed an automated design methodology using a line of sight based algorithm to generate preliminary cooling channel designs [7]. Again simulations showed the method to be promising. As with most conventionally designed cooling circuits, these design automation strategies adopt circular cooling channels. This is likely to be because the axis-symmetric cross-section reduces design complexity and manufacturing issues. However, circular cross-sections also restrict how close the channels can be to the mould surface as a certain minimum offset distance must be left to ensure uniform surface temperatures. The work of Altaf et al. [8] and Shayfull et al. [9] shows the benefit of using $U$ shaped and square profiles respectively to provide more uniform heat transfer to the mould surface.

A recent development by $\mathrm{Au}$ and Yu was the introduction of a conformal layer consisting of interconnected scaffold or porous elements $[10,11]$. The scaffold elements provide structural support whilst helping to disperse coolant throughout the layer. Simulations showed the improved heat transfer and temperature uniformity, however no physical testing results were presented.

A critical issue often overlooked in literature on conformal cooling is the design for manufacture issues associated with metal AM methods. Most important of these is the need for support structures for overhangs, bridges and nested surfaces. With highly complex circular channels or interconnected scaffolds there is a need to ensure the features can be built successfully without the need for support structures, as they are extremely difficult to remove post build and restrict fluid flow [12].

The primary aim of this paper is to design and test conformal cooling layers with easy to build support lattices for efficient and balanced heat transfer. First the general design methodology for creating conformal layers is described. Then the experimental method is presented including the design and testing of simplified test pieces. Finally a virtual injection moulding case study is used to demonstrate the benefits of the method when applied to injection moulding.

\section{Design methodology}

The design methodology is similar to that outlined by Au and Yu [10]. The mould wall is first created by offsetting from the cavity surface (or part model). A second larger offset is used to define the depth 
of the cooling layer, as shown in figure 1. From the second surface the outside of the mould is defined.

A lattice structure is then created by patterning unit cells to fill the overall conformal layer dimensions. The two models are then superimposed and any redundant lattice structure may be removed. Other features such as inlet and outlet ports, guide vanes and alignment features are added last.

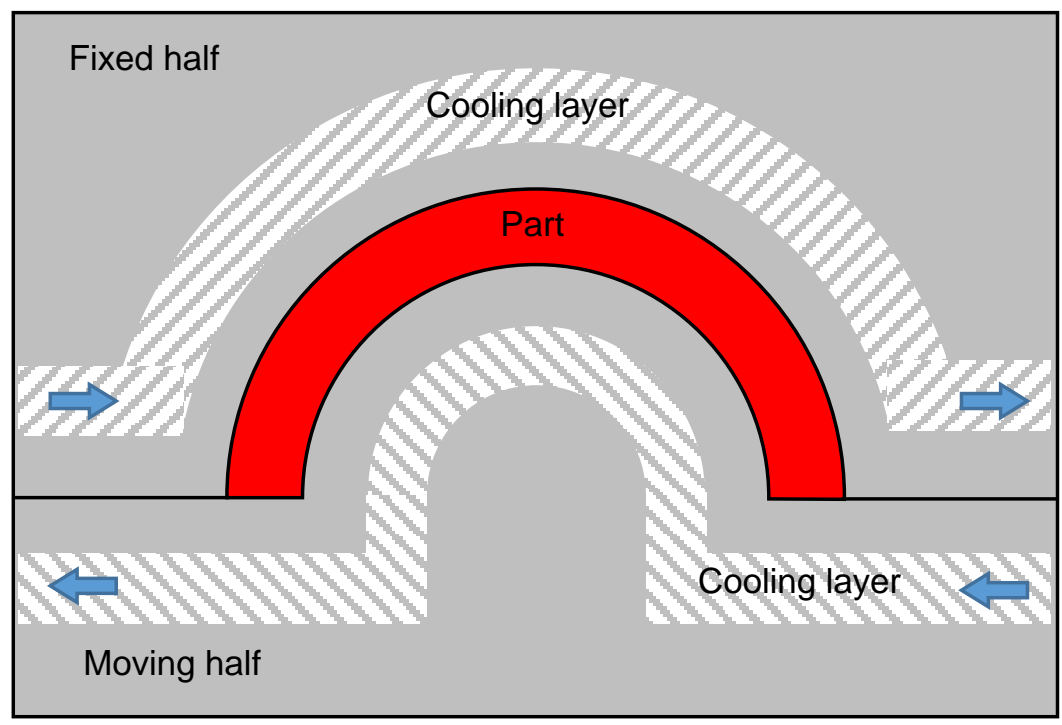

Figure 1. Schematic injection moulding tooling with conformal cooling layers.

The design of the lattice structure will vary from case to case however the main considerations are that all struts are (ideally) over $45^{\circ}$ from the horizontal to prevent build errors, and with low enough aspect ratios to prevent buckling [12]. The length of unsupported overhang on the upper surface of the cooling layers should be as small as possible while not impeding flow. This is to ensure the upper cavity surface has sufficient support. The unit cells also need a base level of symmetry to ensure successful patterning.

In practice it may be that only the convex side of the mould requires a conformal cooling layer. As the polymer on the concave side of the part usually cools more slowly it is this area that will often benefit the most from conformal cooling layers. By being selective with the placement of the conformal layers (by using tooling inserts) the overall tooling costs can be mitigated. 


\subsection{Design of thermal transfer test pieces}

In order to test the heat transfer characteristics of conformal cooling layers three test pieces were manufactured on a Renishaw AM250 with Al10SiMg powder. The choice of material was based on what the machine was loaded with at the time. The test pieces were designed to represent one half of a small injection moulding tool, with a flat cavity surface, in order to simplify the application of a thermal load (figure 2). The lattice dimensions are $95 \times 35 \times 15 \mathrm{~mm}$ and the mould wall is $3 \mathrm{~mm}$ thick. The manifolds were fabricated from plain carbon steel.

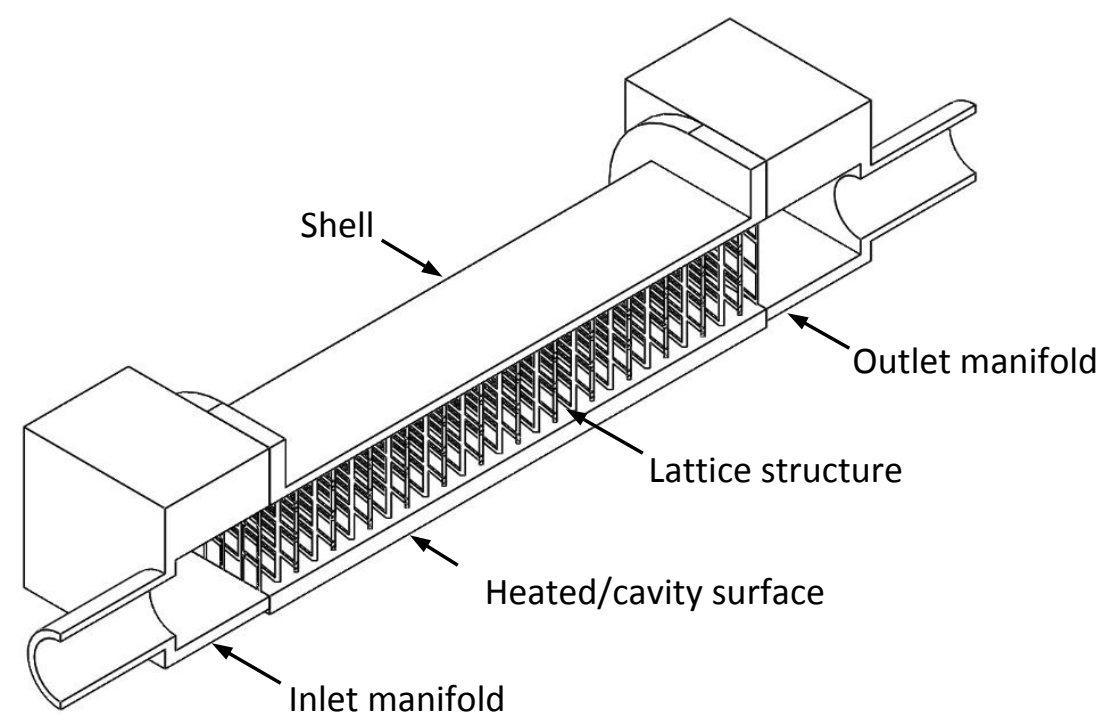

Figure 2. Sectioned thermal transfer test piece showing internal lattice structure.

Figure 3 shows the unit cell geometries used in the test pieces. The struts were chosen to be $0.5 \mathrm{~mm}$ thick and the cells fit within a $5 \mathrm{~mm}$ cube. $0.5 \mathrm{~mm}$ thick struts were chosen based on advice from Renishaw engineers to provide minimum resistance to fluid flow whilst maintaining reliable builds. Ideally the unit cell would feature fillets to reduce stress concentrations however these were omitted in order to reduce the CAD file size and simulation time. 

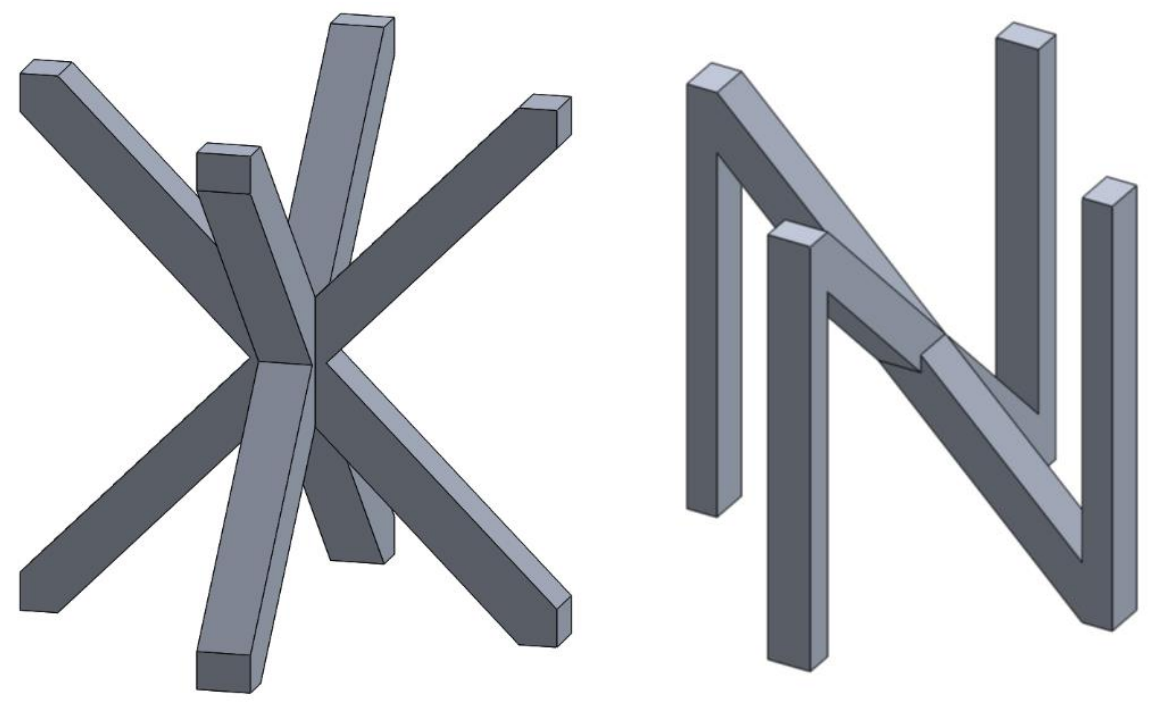

Figure 3. Unit cells: Cross (left) and N (right).

A final test piece was designed featuring two straight $15 \mathrm{~mm}$ diameter holes spaced $19 \mathrm{~mm}$ between centres so that a comparison may be made between circular cooling channels and the lattice filled cooling layers.

\section{Thermal transfer testing}

This section describes the experimental procedure used to measure the heat transfer characteristics of the test pieces. The results of the experiment are summarised and discussed.

\subsection{Experimental procedure}

The test arrangement is presented schematically in figure 4 . The flow rate was controlled by adjusting the wall tap and monitoring the flow meter until a nominal flow rate of $1.5 \mathrm{l} / \mathrm{min}$ was achieved. In practice the flow rate was found to vary with a standard deviation of $0.1 \mathrm{l} / \mathrm{min}$, therefore readings were taken at regular intervals so that an average flow rate could be calculated. The test pieces rested on a $131 \times 92 \times 30 \mathrm{~mm}$ block of aluminium which acted as the heat source for the test piece and a heat sink for the hot plate. The thermal mass of the aluminium block was essential for evening out the power from the $1,200 \mathrm{~W}$ halogen hot plate which used an ON/OFF modulating control strategy. The hot plate was consistently set to half its maximum value. 


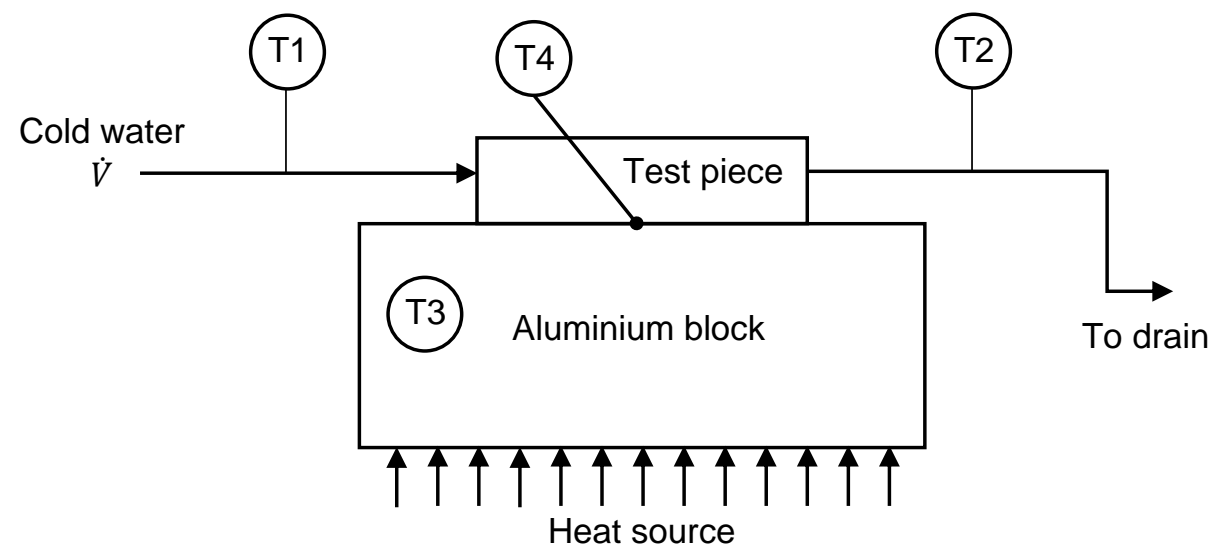

Figure 4. Schematic of thermal flow test apparatus.

The system was allowed to stabilise for 10 minutes before taking measurements. For each test piece 12 sets of measurements were taken approximately three minutes apart. Each set of measurements included the flow rate $\dot{V}$, the inlet fluid temperature $\mathrm{T} 1$, the outlet fluid temperature $\mathrm{T} 2$, the aluminium block temperature T3, and the midpoint edge temperature between the test piece and the aluminium block T4. Over the period of testing the ambient temperature remained in the region of 20 to $21^{\circ} \mathrm{C}$. All temperature measurements were taken with K-type thermocouples.

\subsection{Results and discussion}

Table 1 summarises the average temperature readings and flowrates for the three test pieces. The flow rate and inlet temperature for the drilled test piece was slightly lower than for the lattice pieces. It was also apparent that the steady state temperature of the aluminium block varied considerably between test pieces. The rate of heat transfer into the water $\dot{Q}$ can be calculated from equation 1, where $c=$ the specific heat of water, $\dot{m}=$ the mass flow rate.

$$
\dot{Q}=c \dot{m}(T 2-T 1)
$$

Table 1. Results of thermal transfer tests.

\begin{tabular}{|c|c|c|c|}
\hline \multirow{2}{*}{ Reading } & Drilled holes & Cross lattice & N lattice \\
\cline { 2 - 4 } & \multicolumn{3}{|c|}{ Mean \pm standard deviation } \\
\hline$\dot{V}(/ / \mathrm{min})$ & $1.5 \pm 0.1$ & $1.6 \pm 0.1$ & $1.6 \pm 0.1$ \\
\hline $\mathrm{T} 1(\mathrm{~K})$ & $18.3 \pm 0.2$ & $18.6 \pm 0.2$ & $18.6 \pm 0.1$ \\
\hline
\end{tabular}




\begin{tabular}{|c|c|c|c|}
\hline T2 $(\mathrm{K})$ & $20.6 \pm 0.2$ & $20.8 \pm 0.2$ & $20.9 \pm 0.1$ \\
\hline T3 $(\mathrm{K})$ & $174 \pm 9.8$ & $155 \pm 6.0$ & $137 \pm 5.3$ \\
\hline T4 $(\mathrm{K})$ & $128 \pm 17$ & $108 \pm 9.3$ & $95.1 \pm 6.8$ \\
\hline$\dot{Q}(\mathrm{~W})$ & $246 \pm 28$ & $253 \pm 13$ & $265 \pm 26$ \\
\hline
\end{tabular}

The results show that the heat transfer rate was lowest for the drilled sample and highest for the $\mathrm{N}$ lattice sample. As expected the temperature of the aluminium block (T3) is inversely related to the heat transfer rate $(\dot{Q})$. Whilst there is a large uncertainty associated with the values the relationship between the variables are consistent with theory.

These results show that the lattice structures achieve higher heat transfer rates than circular channels with comparable hydrodynamic diameters, flow rates and inlet temperatures.

The next section describes an FEA simulation built using the average flow rate and inlet temperatures acquired above. The simulation will be validated by comparing the bulk fluid outlet temperature with those from the experimental tests.

\subsection{Thermo-fluid FEA and validation}

Measuring the temperature of the surface in contact with the heat source proved difficult. Hence it was decided to simulate the thermal transfer tests so that the temperature gradients of the bottom surface as well as internal temperature gradients may be approximated. The main body of the test pieces and the manifolds were modelled as Al10SiMg and plain carbon steel respectively. The inlet flow rate and temperature were set as the averages measured during the experimental tests. The test pieces were assumed to be $100 \%$ efficient at transferring heat from the bottom surface into the water. This allowed the heat transfer rates calculated in table 1 to be used as surface heat sources on the underside of the test pieces.

To validate the model the bulk average water temperature at the outlet was compared with the measured outlet temperature in table 1 . The results show good agreement between the measured and simulated outlet temperatures. From the simulation it was also possible to find the change in 
pressure across the test pieces. The lattices were found to require a larger pressure differential, however they were simulated with slightly higher flow rates.

Table 2. Summary of FEA validation data.

\begin{tabular}{|c|c|c|c|}
\hline & Experimental results & \multicolumn{2}{|c|}{ FEA results } \\
\cline { 2 - 4 } & Outlet temperature $\left({ }^{\circ} \mathrm{C}\right)$ & Outlet temperature $\left({ }^{\circ} \mathrm{C}\right)$ & Pressure \\
& & & $(\mathrm{Pa})$ \\
\hline Drilled holes & 20.6 & 20.7 & 107 \\
\hline Cross lattice & 20.8 & 20.8 & 151 \\
\hline N lattice & 20.9 & 21.0 & 149 \\
\hline
\end{tabular}

Figure 5 shows mid-plane and surface temperature plots of the three test pieces. The cut plots were taken at the mid points and the same thermal scale is used for all images. The hot and cold sections are shown as white and black respectively. The surface temperatures of the lattice structures are significantly cooler than the drilled sample and have much shallower thermal gradients. This indicates that not only are the lattices superior at removing heat but are likely to reduce warping due to uneven cooling. 

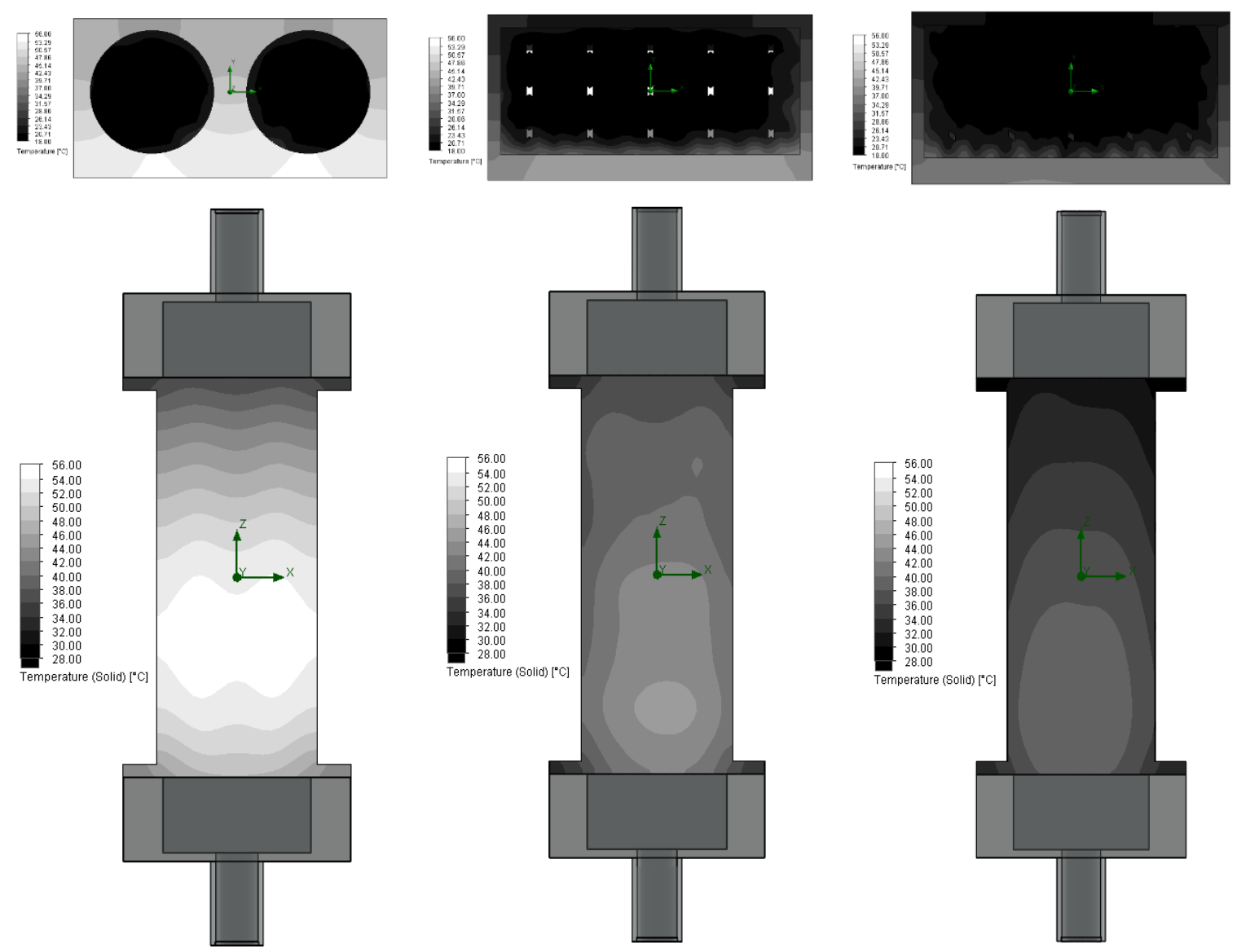

Figure 5. FEA mid-plane and bottom surface temperature plots of the three test pieces, drilled holes (left), cross lattice (centre), $N$ lattice (right).

The reason for the improved heat transfer appears to be much higher fluid/solid interfacial areas and increased vorticity in the fluid, improving the convective heat transfer within the boundary layers.

Simulations showed the vorticity in the latticed samples was more evenly spread throughout the fluid volume compared to the drilled sample. In addition the $\mathrm{N}$ lattice has vertical struts which allow more direct conduction of heat from the heated surface deep into the fluid (figure 6). 


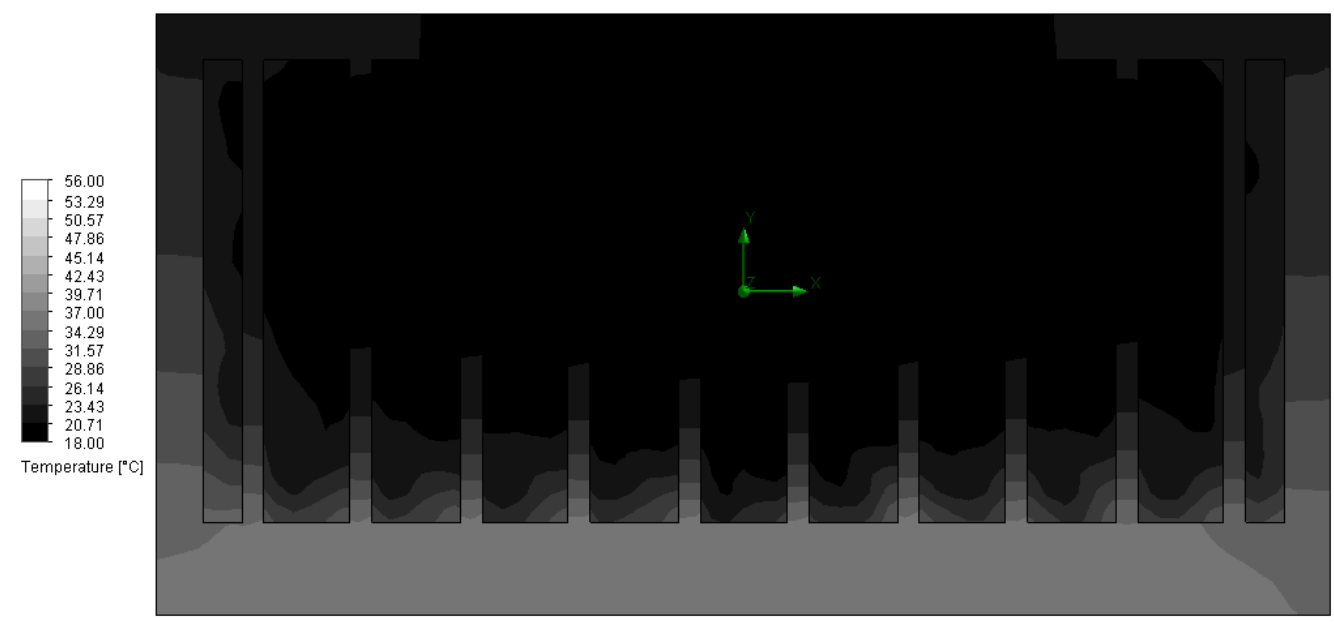

Figure 6. Cross-section of the $\mathrm{N}$ lattice showing the thermal gradient in the vertical struts.

\section{Compression testing}

Compression testing of the lattices was carried out to investigate their load carrying capacity. The same unit cells outlined in section 2.1 were used to create cuboidal lattices with $6^{3}$ unit cells (figure 7 ). The diamond lattice is identical to the cross lattice but is closed at the top and bottom instead of open to test the effect of boundary conditions. The lattices were tested on a Testometric FS100SCCT $100 \mathrm{KN}$ universal testing machine with a constant strain rate of $2.5 \mathrm{~mm} / \mathrm{min} .1 \mathrm{~mm}$ aluminium shims were placed between the lattices and the compression platens. The tests were carried out in triplicate.
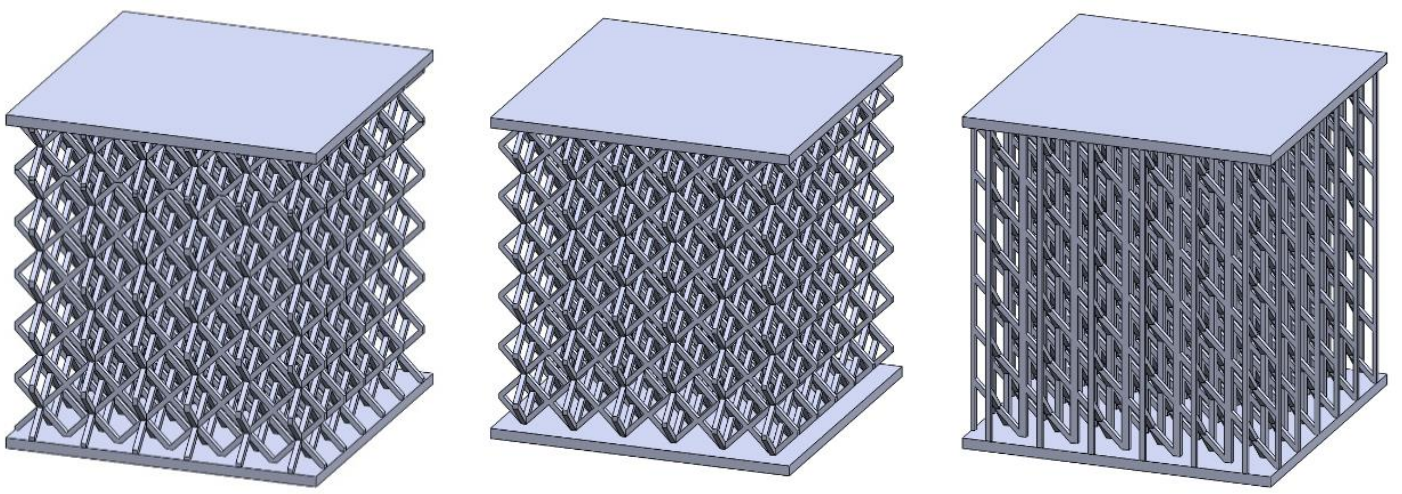

Figure 7. a) CAD images of cross, diamond and $N$ cell lattices with $1 \mathrm{~mm}$ shims. 
Figure 8 shows a typical compression curve for each lattice type. Due to manufacturing flaws there was significant variation in the amplitude of the forces, however the general shape of the curves was found to be consistent for each lattice type. The Diamond and $N$ type lattices were found to support constant loads over large deformation ranges. The $\mathrm{N}$ lattice was found to be significantly stiffer than the other lattices at low strains, due to the vertical struts.

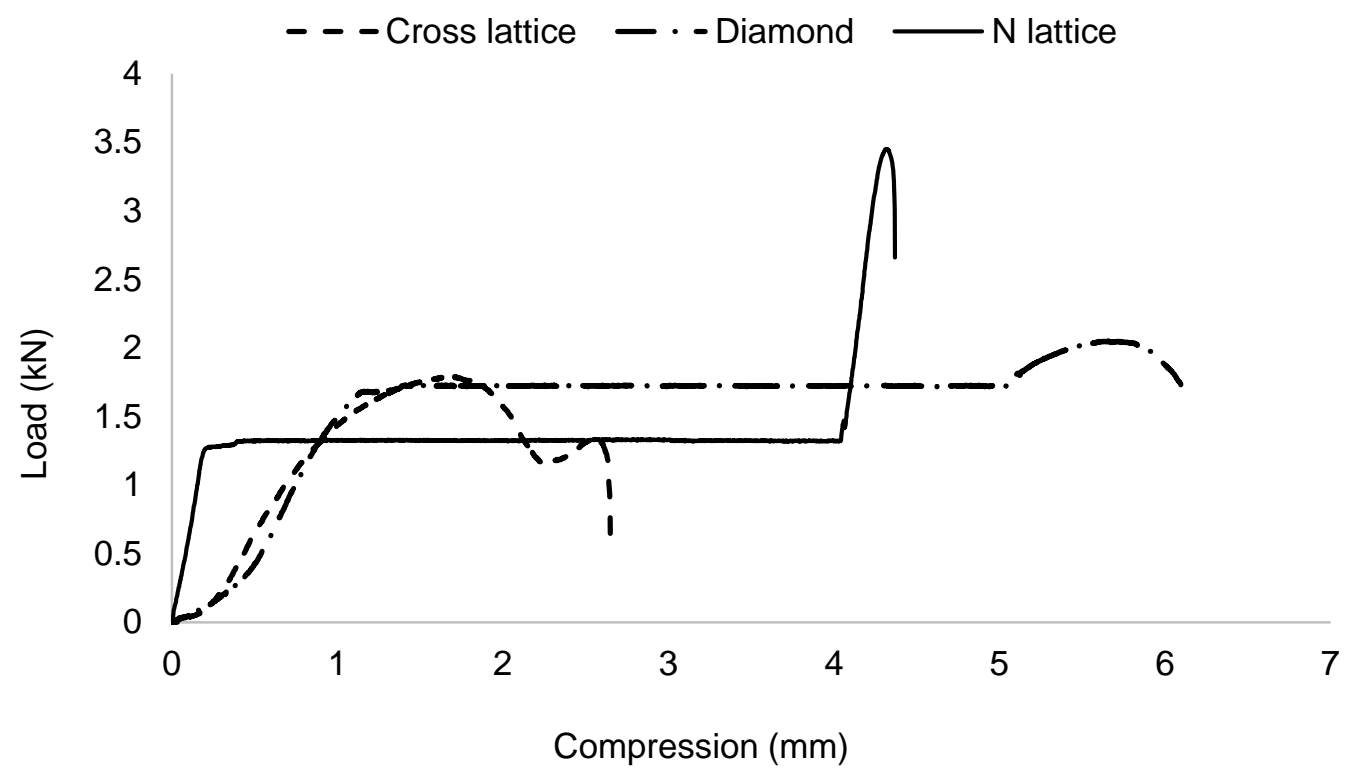

Figure 8. Typical load-compression curves for each lattice type.

A load of $1.7 \mathrm{kN}$, like that achieved by the cross lattice, corresponds to a pressure of $1.9 \mathrm{MPa}$ over the area of the lattice. As injection moulding packing pressures can reach over $100 \mathrm{MPa}$, stronger lattices will likely be required. This is not considered a problem as it is possible to significantly increase the thickness of the struts as the density of the tested lattices was very low $\left(136 \mathrm{~kg} / \mathrm{m}^{3}\right.$ for the cross lattice or $94.9 \%$ space). Recent developments in CAD software such as Autodesk® Within, could allow for straightforward structural optimisation of the lattices in future tooling designs.

\section{Case study}

A virtual case study was carried out in order to compare the performance of conformal cooling layers with conventional and conformal cooling channels. The focus of the case study is an injection moulded rectangular enclosure. This is a very common geometry used for a wide range of consumer products. Despite the wide spread use of this geometry it is difficult to cool using conventional cooling 
channels due to the large internal convex surface. The simulations were carried out in Solidworks Plastics Advanced 2014 SP4.0. The enclosure dimensions are $100 \times 68 \times 40 \mathrm{~mm}$ and $2.5 \mathrm{~mm}$ thick (figure 9).

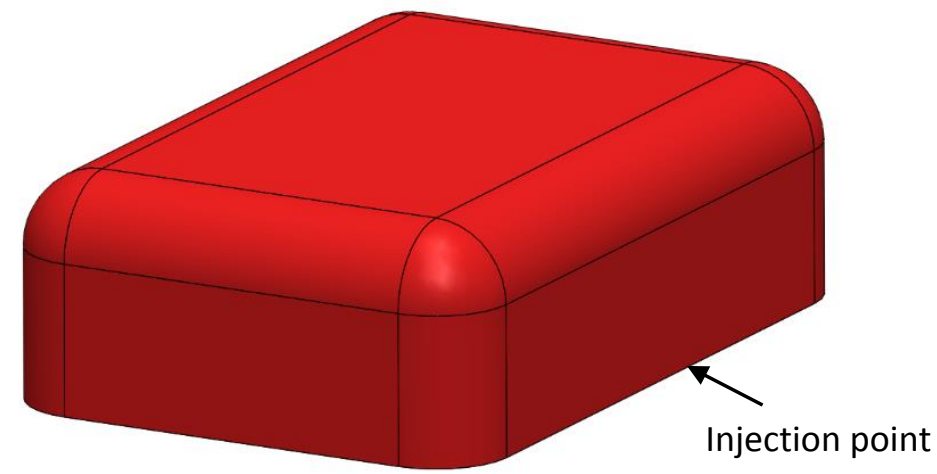

Figure 9. Rectangular enclosure used for the virtual case study.

In practice it is common for both halves of the enclosure to be moulded side by side to reduce downstream handling time. For this reason the injection point was chosen to be on the long edge, however to reduce simulation time only one impression will be included in the simulations.

Three different cooling systems were designed. Cooling system 1 (CS1) featured conventionally drilled cooling channels. Cooling system 2 (CS2), is identical to CS1 except for the lower cooling circuit which is conformal to the internal surface. The internal conformal channels would require additive manufacture. Both CS1 and CS2 were designed following common design guidelines to achieve a good balance between heat transfer and even cooling, as follows:

- All conventional channels are $\varnothing 8 \mathrm{~mm}$ with centres offset $12 \mathrm{~mm}$ from the mould surface and $16 \mathrm{~mm}$ apart.

- All conformal channels are $\varnothing 6 \mathrm{~mm}$ with centres offset $9.5 \mathrm{~mm}$ from the mould surface and 14 $-16 \mathrm{~mm}$ apart.

- Three separate loops were used each with an average flow rate of $150 \mathrm{cc} / \mathrm{s}$ and an inlet temperature of $30^{\circ} \mathrm{C}$.

Cooling system 3 (CS3) is modelled as two conformal layers, summarised as follows:

- Each cooling layer is offset $3 \mathrm{~mm}$ from the mould surface and is $5 \mathrm{~mm}$ thick. 
- Funnelled inlets and outlets were added to help spread the flow.

- The lattice structure was omitted to reduce simulation time, however this should provide conservative results.

- To match the overall flow rate of CS1 and CS2 each layer was modelled with an average flow rate of $225 \mathrm{cc} / \mathrm{s}$ and an inlet temperature of $30^{\circ} \mathrm{C}$.

Default settings included water as the cooling fluid, 420 stainless steel as the mould material and default machine (Simpoe-mold) as the injection moulding machine. The polymer was generic ABS from the Solidworks Plastics Advanced polymer database, with an injection temperature of $230^{\circ} \mathrm{C}$ and an ejection temperature of $120^{\circ} \mathrm{C}$.

Solid meshes were used for the cavity, cooling circuits and mould. First an initial cooling analysis was carried out with a mould reference temperature of $50^{\circ} \mathrm{C}$, followed by a flow analysis. The process was then iterated using the results of the flow analysis to feed back into the cooling analysis to allow for more realistic initial conditions. Finally flow, packing and wrap analysis were carried out to complete simulations of the full injection moulding cycles.

Figure 10 shows the results of the mould surface temperature at the end of cooling for CS1 and CS2. There is a wide variation in the temperature for CS1 (approximately $40-88^{\circ} \mathrm{C}$ ), with high temperatures in the moving half of the mould. The conformal cooling channel in CS2 greatly reduces the temperature range (approximately $40-63^{\circ} \mathrm{C}$ ).
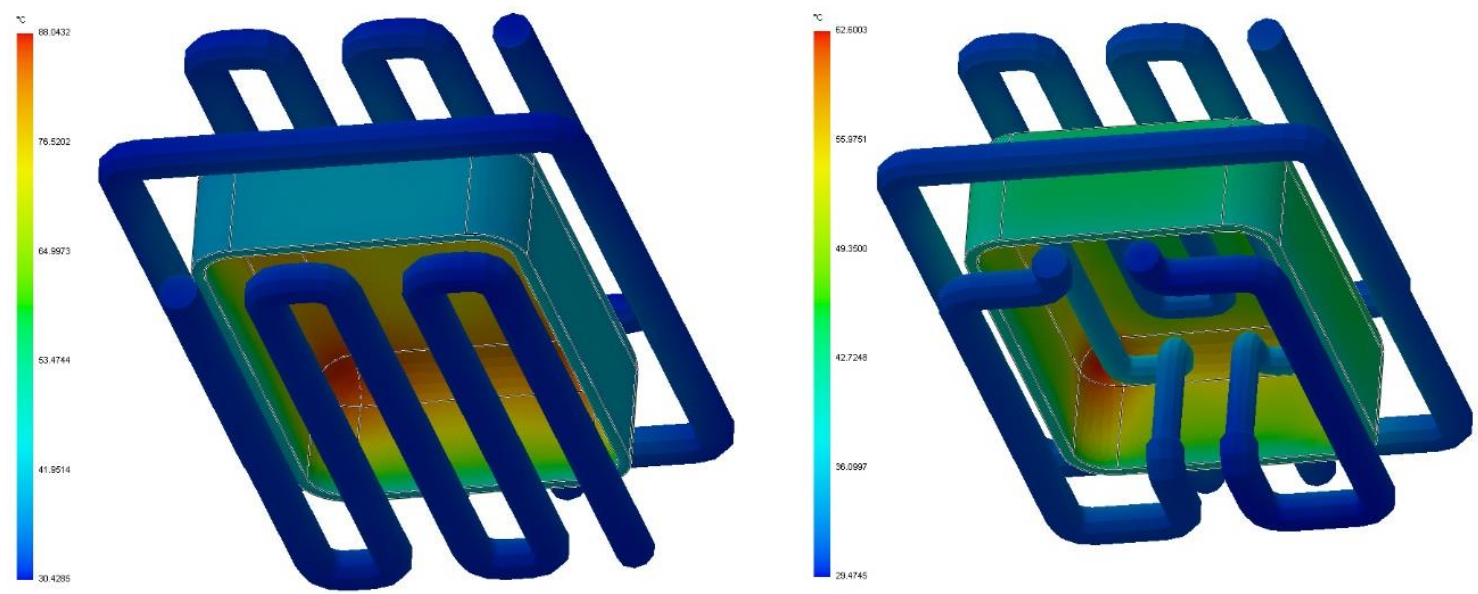

Figure 10. Mould temperature after cooling for CS1 (left), and CS2 (right). 
Figure 11 shows the mould temperature after cooling for CS3, with and without the cooling layers visible. The variation in temperature is much lower than for CS1 and CS2 (approximately $35-40{ }^{\circ} \mathrm{C}$ ) due to the higher heat transfer rate and more even coverage.
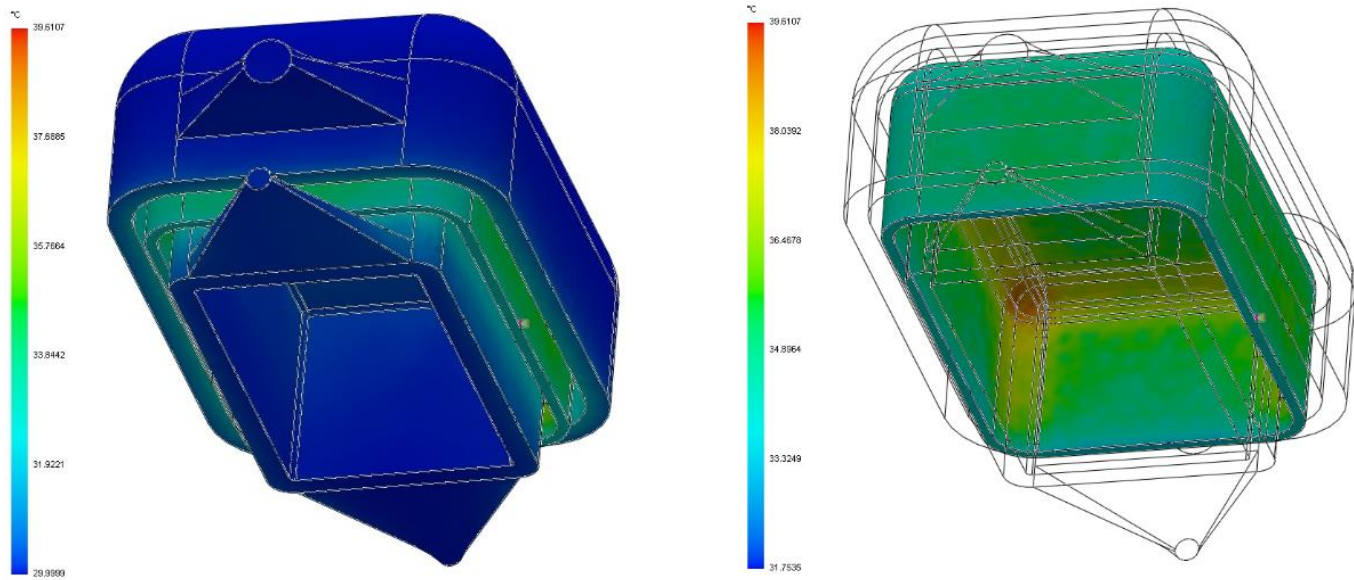

Figure 11. Mould temperature after cooling for CS3 with cooling layers visible (left) and hidden (right).

Reducing the mould temperature after cooling helps to keep the average mould temperature over the injection moulding cycle low, which has a direct influence on part cooling time. In addition to this reduced temperature variation helps to improve part quality by reducing warpage and sink marks. Table 3 summarises the important results from the simulations. The cooling time is defined as the time required for over $90 \%$ of the polymer thickness at that location to be below the ejection temperature.

Table 3. Summary of simulation results. Data shown is the plot maximums from flow, warp and cooling analyses.

\begin{tabular}{|l|c|c|c|}
\hline & $\begin{array}{c}\text { Conventional cooling } \\
\text { channels (CS1) }\end{array}$ & $\begin{array}{c}\text { Conformal cooling } \\
\text { channels (CS2) }\end{array}$ & $\begin{array}{c}\text { Conformal } \\
\text { layers (CS3) }\end{array}$ \\
\hline
\end{tabular}




\begin{tabular}{|c|c|c|c|}
\hline Cooling time $(\mathrm{s})$ & 23.18 & 19.02 & 17.08 \\
\hline Warpage $(\mathrm{mm})$ & 0.937 & 0.811 & 0.863 \\
\hline Sink marks $(\mathrm{mm})$ & 0.0129 & 0.0112 & 0.0106 \\
\hline $\begin{array}{c}\text { Cycle averaged mould } \\
\text { temperature }\left({ }^{\circ} \mathrm{C}\right)\end{array}$ & 93.09 & 62.60 & 46.23 \\
\hline \multicolumn{2}{|c|}{ Reduction in cooling time compared to CS1 } & $17.96 \%$ & $26.34 \%$ \\
\hline
\end{tabular}

Based on the results above the conformal cooling layers were successfully able to reduce the cooling time over circular cooling channels. The warping was found to be higher than for conformal channels but lower than conventional channels, whilst sink marks were reduced. All simulations indicated successful filling.

It is likely that for CW3 only the bottom (or moving) half of the mould needs to have conformal layers to achieve a similar performance. Assuming this in the case then the tooling costs for CW2 and CW3 would be very similar.

\section{Conclusion}

Conventionally drilled channels in tooling are not capable of achieving optimal geometries for complex impression shapes in a balanced fashion. In order to overcome these short falls additive manufacturing is currently being adopted to manufacture conformal cooling channels. Whilst significantly increasing performance, the design of these cooling channels is often time intensive and are still restricted by design rules required to minimise uneven cooling. To overcome these limitations new conformal cooling layers with self-supporting lattice structures are introduced. The lattices are constructed from simple unit cells and designed with self-supporting angles for AM.

The effectiveness of the cooling layers was verified via experimental testing and simulation. The lattice structures were found to increase heat transfer over circular channels due to increased interfacial surface areas and fluid vorticity. Simulations, which were verified by experimental data, showed significantly lower thermal gradients on the heated surface. The cooling layers are likely to 
find applications in high performance tooling were high heat transfer rates and/or thermal balancing is critical. Examples could include; injection moulding, blow moulding, extrusion and die casting.

Compression testing revealed that the strength of the lattice structures will need to be carefully designed in order to prevent deflection in high pressure areas. The compression characteristics of the three lattice types were found to vary widely demonstrating how lattices could be used to tailor parts with a wide range of mechanical properties.

A virtual case study was conducted using Solidworks Plastics Advanced 2014 to compare three different cooling systems for a rectangular enclosure. The conformal layers preformed favourably against conventional cooling channels reducing the cooling time by $26.34 \%$ and the severity of sink marks.

\section{References}

[1] Schmidt WR, White RD, Bird CE, Bak J V. Conformal Cooling Versus Conventional Cooling: An Injection Molding Case Study With P-20 and 3DP ${ }^{T M}$-Processed Tooling. MRS Proc., vol. 625, Cambridge Univ Press; 2000, p. 51.

[2] Shayfull Z, Sharif S, Zain AM, Ghazali MF, Saad RM. Potential of Conformal Cooling Channels in Rapid Heat Cycle Molding: A Review. Adv Polym Technol 2014;33:n/a - n/a. doi:10.1002/adv.21381.

[3] Au KM, Yu KM. Conformal cooling channel design and CAE simulation for rapid blow mould. Int J Adv Manuf Technol 2013;66:311-24. doi:10.1007/s00170-012-4326-6.

[4] Hölker R, Jäger A, Ben Khalifa N, Tekkaya AE. Controlling heat balance in hot aluminum extrusion by additive manufactured extrusion dies with conformal cooling channels. Int $\mathrm{J}$ Precis Eng Manuf 2013;14:1487-93. doi:10.1007/s12541-013-0200-1.

[5] Armillotta A, Baraggi R, Fasoli S. SLM tooling for die casting with conformal cooling channels. Int J Adv Manuf Technol 2014;71:573-83. doi:10.1007/s00170-013-5523-7.

[6] Wang Y, Yu K-M, Wang CCL, Zhang Y. Automatic design of conformal cooling circuits for rapid tooling. Comput Des 2011;43:1001-10. doi:http://dx.doi.org/10.1016/j.cad.2011.04.011.

[7] Au KM, Yu KM, Chiu WK. Visibility-based conformal cooling channel generation for rapid tooling. Comput Des 2011;43:356-73. doi:http://dx.doi.org/10.1016/j.cad.2011.01.001.

[8] Altaf K, Majdi Abdul Rani A, Raghavan VR, Rani AMA, Raghavan VR. Prototype production and experimental analysis for circular and profiled conformal cooling channels in aluminium filled epoxy injection mould tools. Rapid Prototyp J 2013;19:220-9.

doi:doi:10.1108/13552541311323236. 
[9] Shayfull Z, Sharif S, Zain AM, Saad RM, Fairuz MA. Milled Groove Square Shape Conformal Cooling Channels in Injection Molding Process. Mater Manuf Process 2013;28:884-91. doi:10.1080/10426914.2013.763968.

[10] Au KM, Yu KM. A scaffolding architecture for conformal cooling design in rapid plastic injection moulding. Int J Adv Manuf Technol 2007;34:496-515. doi:10.1007/s00170-006-0628-x.

[11] Au KM, Yu KM. Modeling of multi-connected porous passageway for mould cooling. Comput Des 2011;43:989-1000. doi:http://dx.doi.org/10.1016/j.cad.2011.02.007.

[12] Wang D, Yang Y, Yi Z, Su X. Research on the fabricating quality optimization of the overhanging surface in SLM process. Int J Adv Manuf Technol 2012;65:1471-84. doi:10.1007/s00170-012-4271-4. 